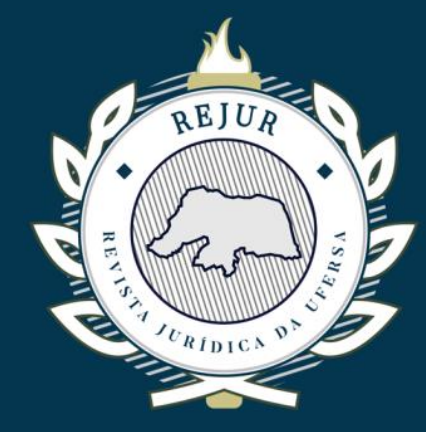

\title{
O VALOR DAS CUSTAS PROCESSUAIS NO TRIBUNAL DE JUSTIÇA NO RIO GRANDE DO NORTE: UMA NOVA PROPOSTA PARA SUA DEFINIÇÃO
}

THE VALUE OF PROCEDURAL COSTS IN THE COURT OF JUSTICE IN RIO GRANDE DO NORTE: A NEW PROPOSAL FOR ITS DEFINITION

RAIMUNDO MÁrCIO RIBEIRO LIMA* | ROBERTO BARROSO MOURA**

RESUMO

O presente estudo visa abordar a temática das custas processuais no sistema judiciário, com enfoque no Tribunal de Justiça do Rio Grande do Norte - TJRN, discutindo sua razoabilidade em razão dos serviços prestados, obstáculos que causam ao gozo do direito de ação em sentido amplo, os fatores que determinam os valores cobrados e a relação com a gratuidade judiciária. A análise do tema permitirá identificar como são definidas as custas judicias e as implicações do valor que lhe é atribuído sobre o exercício do direito de ação. Ou seja, enfrenta-se o problema dos valores cobrados para acesso ao sistema judiciário e as implicações disso para mover a jurisdição. Assim, pretende-se demonstrar argumentos que justificarão uma revisão da forma como o tema é abordado, apresentando os principais embates sobre a matéria, indicando o posicionamento da doutrina e da jurisprudência, em especial, do Supremo Tribunal Federal. Para tanto, analisa-se dados coletados juto ao Conselho Nacional de Justiça, ao Instituto Brasileiro de Geografia e Estatística e ao TJRN. Assim, demonstrar-se-á que é necessário repensar a forma como é realizado o cálculo que define o valor das custas judiciais para que haja maior sinalagma entre os serviços prestados e os valores cobrados.

\section{ABSTRACT}

This study aims to address the issue of court costs in the judiciary system, focusing on the Court of Justice of Rio Grande do Norte - TJRN, discussing its reasonableness due to the services provided, obstacles that cause the enjoyment of the right to action in a broad sense, the factors that determine the amounts charged and the relationship with legal gratuity. The analysis of the theme will allow us to identify how the court costs are defined and the implications of the value attributed to it on the exercise of the right of action. That is, we face the problem of the amounts charged for access to the judiciary and the implications of this to move the jurisdiction. Thus, it is intended to demonstrate arguments that will justify a review of the way the topic is approached, presenting the main clashes on the subject, indicating the position of the doctrine and jurisprudence, especially of the Supreme Court. To this end, data collected from the National Council of Justice, the Brazilian Institute of Geography and Statistics and the TJRN are analyzed. Thus, it will be demonstrated that it is necessary to rethink the way the calculation that defines the value of the costs is performed so that there is greater signal between the services rendered and the amounts charged.

Palavras-chave: custas processuais; taxa; Keywords: procedural costs; tax; reasonability. razoabilidade.

* Doutor em Direito Constitucional pela Universidade Federal do Ceará (UFC). Doutorando em Direito Público pela Universidade de Coimbra (Portugal). Professor do Curso de Direito da Universidade do Estado do Rio Grande do Norte (UERN). Procurador Federal. marcio.ribeiro@ufersa.edu.br

\footnotetext{
** Especialista em Direito Constitucional e Tributário pela Universidade Federal Rural do Semi-árido (UFERSA). Consultor Jurídico da Associação da Polícia Militar de Mossoró e Região.

robertobarrosoadv@hotmail.com
} 


\section{SUMÁRIO}

\section{INTRODUÇÃO; 1 NATUREZA JURÍDICA, COMPETÊNCIA PARA CRIAÇÃO E BASE DE CÁLCULO DAS CUSTAS JUDICIAIS; 2 CRÍTICA DA BASE DE CÁLCULO DAS CUSTAS JUDICIAIS COM ENFOQUE NO TJRN; 3 PROPOSTA PARA DEFINIÇÃO DO VALOR DAS TAXAS JUDICIÁRIAS NO TJRN; CONSIDERAÇÕES FINAIS.}

\section{INTRODUÇÃO}

O valor das custas judicias é tema que merece análise diante da percepção de ausência de proporcionalidade, por não existir uma razoável correlação entre valor cobrado e serviço prestado, que os operadores do direito, em especial os advogados e seus constituintes, intuem diante das custas cobrados pelo judiciário para permitir que seja movida a jurisdição, a fim de que se tenha uma resposta de mérito às demandas propostas.

Portanto, é precioso todo questionamento que vise discutir o problema da razoabilidade do valor das custas judiciais em comparação com os serviços prestados pelo judiciário, bem como, os obstáculos que eventualmente causam ao exercício do direito de ação em sentido amplo e, ainda, os fatores que determinam os valores das custas e a relação entre a quantidade de concessão da gratuidade judiciária e os montantes cobrados.

Diante do tamanho territorial de nossa nação, dividida em 26 estados e um Distrito Federal, possui uma elevada quantidade de Tribunais, alargada em razão das especializações dos órgãos julgadores, os quais possuirão regulamentações próprias para as cobranças das custas judiciais. Dessa monta, para melhor aproveitamento, o estudo se limita ao TJRN, sem descuidar que se parte da hipótese que a ausência de razoabilidade quanto à fixação dos valores das custas é problema que perpassa por muitos Estados da Federação.

A importância da pesquisa é evidente, pois permitirá uma análise sobre os valores cobrados a título de custas judiciais, sua natureza jurídica, suas implicações para as partes processuais e os reflexos do montante cobrado para com relação ao acesso à jurisdição. 0 estudo pretenderá indicar, ainda, soluções ou rumos para que as eventuais discrepâncias entre valores cobrados em relação à natureza das demandas propostas ou serviços prestados sejam minimizadas, permitindo um maior e mais justo acesso à jurisdição no Rio Grande do Norte.

Pretende-se, ainda, discutir os valores cobrados pelo judiciário potiguar para que seja movida a jurisdição, a fim de demonstrar que estar, em alguns casos, ferindo princípios basilares do ordenamento jurídico brasileiro, bem como, analisar a forma de realização do cálculo do valor do tributo que não é, muitas vezes, proporcional ao serviço prestado, inclusive, discutir se tal formato dificulta ou impede o acesso ao Judiciário, no Rio Grande do Norte, por parte de alguns pretensos jurisdicionados.

Do ponto de vista metodológico, foi dado enfoque na pesquisa descritiva sobre o tema proposto, partindo de uma análise bibliográfica e jurisprudencial sobre o assunto, bem como, 
estudo documental e análise de dados coletadas junto ao Poder Judiciário, tudo para permitir uma pesquisa quantitativa dos dados que serão analisados a fim de que seja proposta uma nova visão sobre o tema.

Ao final, pretende-se considerar a possibilidade de uma nova fórmula para a definição do valor das custas processuais no TJRN. Nesse sentido, indica-se a necessidade da existência de uma base de cálculo sobre a qual se deve aplicar alíquotas variáveis em razão de determinadas características das demandas que serão propostas, de forma que seja possível uma maior sinalagma entre montantes cobrados e os serviços prestados pelo Tribunal.

\section{NATUREZA JURÍDICA, COMPETÊNCIA PARA CRIAÇÃO E BASE DE CÁLCULO DAS CUSTAS JUDICIAIS}

No intuito de iniciar a análise do tema proposto para investigação é necessário trilhar um caminho, o qual se inicia com a identificação da natureza jurídica das custas judiciais. Só então, partindo desta realidade, é que será possível aprofundar corretamente um exame sistemático do tema.

Antes, deve-se esclarecer que custas judiciais é gênero, a comportar três espécies: taxa judiciária, custas judiciais em sentido estrito e emolumentos. A taxa judiciária pode será cobrada em razão da atuação dos magistrados e membros do Ministério Público; as custas, por sua vez, são devidas pelos encargos realizados pelos serventuários da justiça; por fim, os emolumentos se relacionam aos serviços notariais e de registro.

O atual estágio de evolução do estudo permite poucas suspeitas quanto à natureza de tributo da exação, tanto do gênero quanto de suas espécies. É verdade que alguns doutrinadores defenderam que a cobrança se adequaria mais a preço público em razão da ausência de compulsoriedade da cobrança. Nessa toada, Bernardo Ribeiro de Morais afirmou que "a cobrança é exigida apenas das pessoas que procuram o aludido serviço, caracterizandose, portanto, numa obrigação ex-voluntante, contratual, não típica dos tributos, mas elemento essencial para os preços públicos ${ }^{1 "}$.

Entretanto, compreendendo-a como tributo, será evidente que surge como uma forma de arrecadação pelo Estado, na modalidade de receita derivada e não originária, de recursos destinados ao bem comum que, no caso das custas judiciais, pode ser identificado como a possibilidade de disponibilidade à jurisdição, visto que sua cobrança é vinculada à prestação do serviço jurisdicional, não se revela salutar, portanto, indicá-la como preço público, mas, sim, como tributo.

Recordando a teoria da pentaparticipação ou quintepartite, aceita pelo Supremo Tribunal Federal ${ }^{2}$, o termo tributo é gênero que comporta as seguintes espécies: imposto, taxa, contribuição de melhoria, empréstimos compulsórios e contribuições especiais. Dentre estas espécies, será o fato gerador em cotejo com a base de cálculo que nos permitirá identificar qual delas é a que se adequa ao tributo analisado.

\footnotetext{
${ }^{1}$ MORAES, Bernardo Ribeiro de. Doutrina e prática das taxas. São Paulo: RT, 1976, p. 108, apud, SABBAG, Eduardo. Manual de Direito Tributário. 9ạ ed. São Paulo: Saraiva, 2017, p. 486.

2 Vide julgados do Recurso Extraordinário no 111.954/PR, DJU 24/06/1988 e AI-AgR 658576/RS, Relator Ministro Ricardo Lewandowski, 1a Turma, Julgamento em 27/11/2007;
} 
Partindo dessa premissa, a Corte Superior firmou entendimento de que as custas judiciais possuem natureza jurídica de taxa. Cumpre frisar que o raciocínio do STF quanto ao tema não é recente, ainda sob a influência da Emenda Constitucional $n=1 / 69$, julgando a Representação no 1.094-SP, em 08/08/1984, a Corte firmou que as custas possuem a natureza jurídica de taxa. Igualmente, durante a vigência do atual Texto Constitucional, é firme a mesma interpretação quanto à natureza jurídica das custas processuais.

Nesse sentido, no julgamento da ADI $1444^{3}$, de relatoria do eminente Ministro SYDNEY SANCHES, julgada em 12/02/2003, declarando a inconstitucionalidade da Resolução $n$ ㅇ 7, de 30 de junho de 1995, do Tribunal de Justiça do Estado do Paraná, que majorava os valores das custas judiciais e extrajudiciais, o STF afirmou que não seria possível a referida majoração sem a publicação de lei, pois dada a natureza de tributo da exação, na modalidade taxa, haveria evidente vinculação ao princípio da legalidade.

Desse modo, dada sua natureza de taxa, comporta algumas características próprias desta espécie tributária, assim, afirma Ricardo Lobo Torres que "a taxa é um tributo contraprestacional, posto que vinculado a uma prestação estatal específica em favor do contribuinte $^{4 \prime}$. Portanto, gozará de referibilidade na medida em que é cobrada em razão de um serviço público dotado de especificidade e divisibilidade, daí ser retributiva ou contraprestacional e não contributiva como seria caso possuísse natureza jurídica de imposto.

Pode-se, acertadamente, afirmar que será tributo vinculado, pois, como ensina a melhor doutrina, o "fato gerador da taxa não é um fato do contribuinte, mas um fato do Estado. O Estado exerce determinada atividade e, por isso, cobra a taxa da pessoa a quem aproveita aquela atividade ${ }^{5 \prime}$. Ou seja, a cobrança está interligada com uma atividade específica voltada ao contribuinte.

Ademais, como a taxa é espécie de Tributo, deverá obedecer aos princípios constitucionais tributários, tais como: legalidade, anterioridade, isonomia e etc. Estando prevista no Texto Constitucional nos artigos $98, \S 2$ 으, e 24, inciso IV, este último, indicando ser de competência concorrente da União, Estados e Distrito Federal legislar sobre custas de serviços forenses. Diante disso, concluiu o estudo realizado pelo Conselho Nacional de Justiça $-\mathrm{CNJ}$ :

Por esse dispositivo, apesar da autonomia estadual quanto à organização da justiça (prevista no art. 125) compete à União a edição de lei nacional contendo normas gerais sobre as custas judiciais no Brasil. Aos estados, caberia a edição de leis específicas obedecendo a lei nacional. Contudo, apesar disso, a lei nacional nunca foi editada e o STF tem entendido que, na ausência dessa norma, valem a leis estaduais sobre a matéria ${ }^{6}$.

\footnotetext{
${ }^{3}$ ADI 1444, Relator(a): Min. SYDNEY SANCHES, Tribunal Pleno, julgado em 12/02/2003, DJ 11-04-2003 PP-00026 EMENT VOL-02106-01 PP-00046

${ }^{4}$ TORRES, Ricardo Lobo. Curso de direito financeiro e tributário. 3a ed. Rio de Janeiro: Renovar, 1996, p. 344.

${ }^{5}$ AMARO, Luciano. Direito Tributário Brasileiro. 14a ed. São Paulo: Saraiva, 2008, p. 31.

${ }^{6}$ CONSELHO NACIONAL DE JUSTIÇA, Perfil da fixação de custas judiciais no Brasil e análise comparativa da experiência internacional. Departamento de Pesquisas Judiciárias, julho de 2010. Disponível em <https://www.conjur.com.br/dl/estudo-departamento-pesquisas.pdf>. Acesso em: 12 out. 2019.
} 
Ou seja, tendo em vista a ausência de lei nacional indicando as normas gerais, os Estados e o Distrito Federal acabam por legislar com maior liberdade para instituir a referida exação, fazendo-o, mediante lei ordinária, pela inteligência do art. 145, II, da CF, o qual afirma que os Estados, além dos outros entes federativos, poderão instituir a espécie tributária taxa.

Todavia, para a realização de sua cobrança, será necessária a fixação de sua base de cálculo a qual permitirá encontrar o valor da exação. Para tanto, relevante atentar para a proibição de que, nos termos do art. $145, \S 20$, da CF, as taxas não possuam base de cálculo própria de imposto, e, ainda, segundo o art. 77 do Código Tributário Nacional - CTN, que não poderá ter base de cálculo ou fato gerador idênticos ao de imposto. Por isso, Navarro Coelho afirma que, inclusive, por determinação constitucional (artigo 145, § 2)), "a taxa, qualquer taxa, não pode ter base de cálculo de imposto enquanto espécie ${ }^{7 \prime \prime}$.

Com isso, se pretende que as taxas, ao contrário dos impostos, tenham por base de cálculo um indicador que possua uma correlação entre serviço prestado ao contribuinte, permitindo que o valor cobrado tenha uma maior aproximação do custo da prestação daquele serviço. Na mesma toada, Hector Villegas concluirá, quanto à fixação do valor da taxa, que não se "pode levar em conta circunstância inerentes à pessoa ou aos bens do obrigado, mas só circunstâncias atinentes à atividade em si mesma, por ser ela e não outra, a hipótese de incidência correspondente às taxas ${ }^{8 "}$. No caso das taxas judiciais, qual seria então a base de cálculo para a cobrança da exação? É o que se pretende responder no próximo tópico.

\section{CRÍTICA DA BASE DE CÁLCULO DAS CUSTAS JUDICIAIS COM ENFOQUE NO TJRN}

Dada à natureza de taxa de serviço das custas judiciais, tem-se que deverá existir uma vinculação entre o fato gerador e a atividade estatal, pois goza de referibilidade em razão de que o serviço prestado de jurisdição é específico e divisível. Tal fato trará a consequência de que o Poder Público não deverá cobrar valores maiores do que o efetivamente gasto pela efetiva disponibilização da jurisdição.

Evidente que muitas vezes a busca deste valor justo é extremamente complexa, pois encontrar o montante exato para a prestação do serviço de jurisdição não é tarefa fácil. Diante disso, podem surgir cobranças de custas judiciais que estejam em desacordo com o efetivo fato gerador que lhe deu causa. Daí a importância da correta definição de sua base de cálculo, em cotejo com a alíquota, as quais serão capitais para a definição do valor do tributo.

Por outro lado, não se deve ter por base de cálculo quaisquer indicadores relativos à capacidade econômica do contribuinte, pois, nesse caso, violar-se-ia o Texto Constitucional que em seu art. 145, § 2ㅇ, veda, expressamente, que as taxas possuam base cálculo própria de imposto. Como é fato notório, a capacidade contributiva é matriz de cobrança da espécie tributária imposto. Nesse sentido:

\footnotetext{
7 COELHO, Sacha Calmon Navarro. Contribuições no Direito Brasileiro. In: MARTINS, Ives Granda da Silva; Mendes, Gilmar Ferreira (Coord.). Tratado de Direito Constitucional. 2 2a ed. São Paulo: Saraiva, 2012, p. 101.

${ }^{8}$ VILLEGAS, Hector. "Verdades e ficções em torno do tributo denominado taxa". In: RDP 17/337 apud ATALIBA, Geraldo. Hipótese de Incidência Tributária. Malheiros Editores. 2004, p. 111.
} 
A assertiva é confirmada pela própria distinção entre a Constituição pretérita e a atual. Enquanto a CR/1967-1969 estipulava que "para cobrança de taxa não se poderá tomar como base de cálculo a que tenha servido para a incidência de imposto" (art. 18, parágrafo 2 ) , a CR/1988 deita que "as taxas não poderão ter base de cálculo própria de impostos (art. 145, parágrafo 2으). No regime anterior, portanto, o que se proibia era a criação de taxas com base de cálculo que já tivesse sido utilizada para algum imposto efetivamente existente ou, ao menos, cuja criação estivesse autorizada pelo texto constitucional. Já na situação atual, veda-se o uso de taxa com base de cálculo típica dos impostos, tributos que são cobrados eminentemente com base na capacidade contributiva do pagante ${ }^{9}$.

Dito isso, ficará evidente a possibilidade de criticar a opção do Rio Grande do Norte, por meio da edição da Lei no 9.278/2009, que, ao dispor sobre as custas processuais e emolumentos, aparentemente definiu o valor da causa como a base de cálculo das custas judiciais no TJRN, sem, contudo, criar mecanismos que aproximem o valor cobrado do serviço prestado, criando tabela que define às custas dos atos processuais de acordo com intervalor de valores atribuídos às causas que lhes são submetidas.

É verdade que STF, por meio da súmula 667, afirmou que "viola a garantia constitucional de acesso à jurisdição a taxa judiciária calculada sem o limite sobre o valor da causa". Contudo, o voto do relator na ADI 3.826, o eminente Ministro Eros Grau, que levou a edição da súmula, é indispensável para compreendê-la:

$O$ requerente sustenta que as normas impugnadas violam o disposto nos artigos 5ㅇ, XXXV; 145, II e § 2ㅇ; 154, I; e 236, § 2ㅇ, da Constituição do Brasil, vez que utilizaram, "como critério para a cobrança das custas ou emolumentos, o valor da causa ou o valor do bem ou negócio subjacente, ou sua avaliação, em face do qual se realiza algum ato de serventia judicial ou extrajudicial" (fl. 3). (...) Assim, com respaldo no entendimento desta Corte, no sentido de que (i) é admissível o cálculo das custas judiciais com base no valor da causa, desde que mantida correlação com o custo da atividade prestada, e de que (ii) a definição de valores mínimo e máximo quanto às custas judiciais afasta as alegações de óbice à prestação jurisdicional e ao acesso à Justiça, voto no sentido da improcedência da ação direta ${ }^{10}$.

Ora, resta evidente que a leitura da súmula deve guardar relação com a natureza jurídica do tributo a que ela se refere. Isso se evidencia pelo enxerto acima que, apesar de indicar o valor da causa como elemento essencial para a definição das custas processuais, não se esquece de afirmar que, também, será necessário que o valor tenha relação com a atividade prestada.

Portanto, em que pese ser possível a utilização do valor da causa como base de cálculo para definição do tributo, a simples utilização de preço fixo sem definição de uma alíquota

\footnotetext{
9 MOREIRA, André Mendes e ESTANISLAU, Cesar Vale. As Taxas e o Princípio da Equivalência entre a sua Arrecadação e os Custos da Atividade Estatal. Revista Dialética de Direito Tributário, São Paulo, no 223, p. 34-50, 2014, p. 35.

${ }^{10}$ BRASIL. Supremo Tribunal Federal. Ação Direta de Inconstitucionalidade no 3.826. Tribunal Pleno. Ministro Relator: Eros Grau, julgamento em: 12-5-2010, DJE 154 de 20-8-2010. Disponível em: <http://www.stf.jus.br/portal/jurisprudencia/menuSumarioSumulas.asp?sumula=2250>. Acesso em: 10 set. 2019.
} 
não é própria da espécie tributária taxa, pois impede que, dada a natureza vinculante deste tributo, exista uma exata correlação entre o serviço prestado e o montante efetivamente cobrado.

Pode-se, portanto, afirmar que a discussão quanto à definição da base de cálculo e da alíquota das custas judiciais estará intimamente ligada à sinalagmatidute do referido tributo, que exige a cobrança de um valor o mais aproximado possível em razão da contraprestação ao serviço prestado, evitando-se um enriquecimento sem motivo do Estado.

No caso do TJRN, optou-se pela definição de custas judiciais a preço fixo, divididas de acordo com fatores de referências variáveis em razão do valor atribuído à causa, fixando-se valor mínimo e máximo para a exação. Em outras palavras, não se possui uma alíquota ou mesmo uma base de cálculo, visto que se optou por estabelecer preços fixos em razão de intervalos dos valores atribuídos à causa.

A título de ilustração, segue abaixo, tabela de custas iniciais do TJRN, com última atualização em 21 de fevereiro de 2018, por meio da Resolução no 4, editada pelo Tribunal, na qual se constou atualização de pouco mais de $21 \%$ (vinte e um por cento) dos montantes que estavam, originalmente, previstos nas tabelas anexas a Lei ㅇ 9.278/2009:

Tabela 1 - Custas Judicias do depósito prévio na primeira instância, no TJRN, Rio Grande do Norte, 2018.

\begin{tabular}{|c|c|c|}
\hline CÓDIGO & DISCRIMINAÇÃO & CUSTAS JUDICIAIS \\
\hline 11001 & Nas causas de valor até $R \$ 10.000,00$ ou inestimável & $\mathrm{R} \$ 184,21$ \\
\hline 11001 & Nas causas de valor superior a $R \$ 10.000,00$ ou até $R \$ 30.000,00$ & $\mathrm{R} \$ 354,25$ \\
\hline 11001 & Nas causas de valor superior a $\mathrm{R} \$ 30.000,00$ ou até $\mathrm{R} \$ 50.000,00$ & $\mathrm{R} \$ 566,81$ \\
\hline 11001 & Nas causas de valor superior a $\mathrm{R} \$ 50.000,00$ ou até $\mathrm{R} \$ 100.000,00$ & $\mathrm{R} \$ 1.133,62$ \\
\hline 11001 & Nas causas de valor superior a $\mathrm{R} \$ 100.000,00$ ou até $\mathrm{R} \$ 150.000,00$ & $\mathrm{R} \$ 2.125,53$ \\
\hline 11001 & Nas causas de valor superior a $\mathrm{R} \$ 150.000,00$ ou até $\mathrm{R} \$ 200.000,00$ & $\mathrm{R} \$ 2.834,05$ \\
\hline 11001 & Nas causas de valor superior a $\mathrm{R} \$ 200.000,00$ ou até $\mathrm{R} \$ 300.000,00$ & $\mathrm{R} \$ 3.542,56$ \\
\hline 11001 & Nas causas de valor superior a $\mathrm{R} \$ 300.000,00$ ou até $\mathrm{R} \$ 400.000,00$ & $\mathrm{R} \$ 4.251,07$ \\
\hline 11001 & Nas causas de valor superior a $\mathrm{R} \$ 400.000,00$ ou até $\mathrm{R} \$ 500.000,00$ & $\mathrm{R} \$ 4.605,33$ \\
\hline 11001 & Nas causas de valor superior a $\mathrm{R} \$ 500.000,00$ ou até $\mathrm{R} \$ 600.000,00$ & $\mathrm{R} \$ 4.959,59$ \\
\hline 11001 & Nas causas de valor superior a $\mathrm{R} \$ 600.000,00$ ou até $\mathrm{R} \$ 700.000,00$ & $\mathrm{R} \$ 5.313,84$ \\
\hline 11001 & Nas causas de valor superior a $\mathrm{R} \$ 700.000,00$ ou até $\mathrm{R} \$ 800.000,00$ & $\mathrm{R} \$ 5.668,09$ \\
\hline 11001 & Nas causas de valor superior a $\mathrm{R} \$ 800.000,00$ ou até $\mathrm{R} \$ 900.000,00$ & $\mathrm{R} \$ 6.022,35$ \\
\hline 11001 & Nas causas de valor superior a $\mathrm{R} \$ 900.000,00$ ou até $\mathrm{R} \$ 1.000 .000,00$ & $\mathrm{R} \$ 6.376,61$ \\
\hline 11001 & Nas causas de valor superior a $\mathrm{R} \$ 1.000 .000,00$ ou até $\mathrm{R} \$ 2.000 .000,00$ & $\mathrm{R} \$ 7.085,12$ \\
\hline 11001 & Nas causas acima de $\mathrm{R} \$ 2.000 .000,00$ & $\mathrm{R} \$ 7.793,64$ \\
\hline 11002 & Cumprimento de carta precatória & $\mathrm{R} \$ 184,21$ \\
\hline 11003 & Apelação Cível e Recurso Adesivo & $\mathrm{R} \$ 184,21$ \\
\hline 11004 & Apelação Criminal em ação penal privada & $\mathrm{R} \$ 184,21$ \\
\hline 11005 & Mandado de Segurança & $\mathrm{R} \$ 184,21$ \\
\hline 11006 & Restauração de autos quando a parte der causa & $\mathrm{R} \$ 184,21$ \\
\hline 11007 & Incidentes processuais & $\mathrm{R} \$ 85,03$ \\
\hline 11008 & Ação Penal Privada & $\mathrm{R} \$ 184,21$ \\
\hline
\end{tabular}

Fonte: TJRN 
A opção do Rio Grande do Norte permite a realização de crítica que atinge o âmago da opção do legislador estadual ao impedir uma exata correlação entre o serviço prestado e o valor efetivamente cobrado, pois na medida em que iguala todos os tipos de procedimentos judiciais, cobrando-o em razão do valor atribuído à causa por meio de preços fixos, deixa de observar que muitas vezes o serviço prestado em demandas de alto valor será mínimo enquanto que demandas de ínfimo valor poderão gerar custos elevados.

Imagine-se o exemplo de um divórcio consensual e uma lide que vise uma indenização de reparação por danos morais sofridos em razão de demora excessiva na fila de uma agência bancária. Mesmo que o divórcio tenha por valor atribuído a causa a quantia de $\mathrm{R} \$ 300.000,00$ (trezentos mil reais), exigirá apenas pouquíssimos atos até a sua homologação, enquanto que uma demanda de danos morais, que poderá ser atribuída o valor de $\mathrm{R} \$ 5.000,00$ (cinco mil reais), poderá ter diversos atos até a sua conclusão. Portanto, a demanda de menor valor terá um custo maior.

O demandante que move a jurisdição para pleitear a reparação pelo dano moral sofrido, poderá, caso não seja beneficiado com a gratuidade judiciária e, evidentemente, não sendo ajuizada nos Juizados Especiais, arcar com o tributo no valor de $\mathrm{R} \$ 184,21$ (cento e oitenta e quatro reais e vinte e um centavos) ${ }^{11}$. Por outro lado, o interessado em simplesmente homologar seu divórcio deverá, pois será praticamente improvável a concessão da gratuidade judiciária, arcar com custas no montante de R\$3.542,56 (três mil, quinhentos e quarenta e dois reais e cinquenta e seis centavos) ${ }^{12}$, o equivalente mais de $1 \%$ (um por cento) do valor atribuído à causa.

Entretanto, os custos que o tribunal terá com a demanda de menor valor será muito maior que os gastos para dispor a jurisdição para o procedimento cujo valor atribuído foi muito maior, pois enquanto o primeiro gerará um processo de conhecimento com alargadas chances da vivência de todas as fases procedimentais, o segundo pleiteia somente uma homologação de acordo, já firmado extrajudicialmente, ao ponto de que será mínima a atuação jurisdicional.

Mesmo assim, a taxa paga pelos proponentes do pedido de homologação do divórcio será quase vinte vezes maior que a do outro jurisdicionado. Não há, portanto, qualquer correlação entre o serviço prestado e o valor cobrado. Recordando que não é próprio da taxa o uso do princípio da capacidade contributiva, pois seu valor não é relacionado com a manifestação de riquezas do sujeito passivo, daí não ser possível defender a opção do Rio Grande do Norte a partir deste prisma.

A partir desse cenário, pode-se explicar o conceito de razoabilidade a partir da lição de Weida Zancaner que indica um ato como não razoável quando, mesmo existindo uma relação lógica entre o fato originário e a medida tomada, "não há adequada proporção entre uns e outros; quando se assentou em argumentos ou em premissas, explicitas ou implícitas que não autorizam do ponto de vista lógico, a conclusão deles extraída ${ }^{13 \prime \prime}$.

\footnotetext{
${ }^{11}$ TJRN, Emissão de boleto para pagamento de FDJ. Disponível em <http://sistemas.tjrn.jus.br/fdj/guias.do>, acesso 28/09/2019.

${ }^{12} / d$.

${ }^{13}$ ZANCANER, Weida. Razoabilidade e moralidade: princípios concretizadores do perfil constitucional do estado social e democrático de direito. Revista Diálogo Jurídico, Salvador, CAJ - Centro de Atualização Jurídica, ano I, №. 9, dezembro, 2001. Disponível em: <http://www.direitopublico.com.br>. Acesso em: 14 de dezembro de 2019.
} 
Daí, pode-se argumentar que há uma ausência de razoabilidade entre o serviço efetivamente prestado e o valor cobrado por sua execução no TJRN. Não há dúvida que a referibilidade nunca será plena, por isso, o legislador deve ter habilidade para estabelecer progressões e piso/teto. Igualmente, deverá zelar para evitar que haja uma correlação entre a capacidade contributiva e o valor da taxa de serviço atribuída às custas judiciais, para que a exação não perca sua característica retributiva que lhe é peculiar.

A análise do exemplo acima, demostra que, apesar da conhecida dificuldade de uma assertiva sinalagma, a taxa de serviço não pode ser tão distante da realidade dos custos que - Estado terá com cada demanda, pois se corre o risco de que um dos contribuintes acabe arcando com os custos efetivos provocados pelo outro, gerando desconfiança de todo o sistema que deixa de ser retributivo e passa a ser contributivo, aproximando-se mais da espécie tributária imposto e distanciando-se da taxa. É o que ocorre no TJRN.

Inclusive, é possível que situações, como a demonstrada no exemplo quanto ao divórcio consensual, acabem por reduzir o acesso à jurisdição, pois, muitas vezes, define-se a possibilidade de a parte dever ou não ser agraciada com o benefício da justiça gratuita em razão do valor atribuído a causa. Isto gera situações de verdadeiro impedimento de acesso ao sistema judiciário, pois o elevado custo inicial da demanda cria uma barreira preliminar intransponível para a grande maioria da população.

Tal barreira pode tornar o custo de acesso ao judiciário tão elevado que somente os mais ricos ou as grandes empresas é que, efetivamente, poderão assumir certos tipos de litígios, de forma que para a grande maioria dos pretensos jurisdicionados os custos com o ajuizamento e processamento da demanda não compensariam a busca pela tutela jurisdicional do Estado. Criticando essa situação, a doutrina afirma:

Pessoas ou organizações que possuam recursos financeiros consideráveis a serem utilizados têm vantagens óbvias ao propor ou defender demandas. Em primeiro lugar, elas podem pagar para litigar. Podem, além disso, suportar as delongas do litígio. Cada uma dessas capacidades, em mão de uma única das partes, pode ser uma arma poderosa ${ }^{14}$.

A barreira criada fere de morte o Texto Constitucional, permitindo a existência de situações que serão excluídas da apreciação do poder judiciário, violando-se o artigo 5으, XXXV, da Constituição da República que, como ensina a melhor doutrina, trata de afirmar "o direito de ação para todas as pessoas e o monopólio do Poder Judiciário para julgar em definitivo as controvérsias jurídicas e declarar direitos ${ }^{15 "}$.

Igualmente, o problema da definição do valor das custas judiciais tem significativo impacto na concessão do benefício da assistência judiciária gratuita no TJRN. Segundo o IBGE ${ }^{16}$, a população do Rio Grande do Norte, com 14 anos ou mais, possui o rendimento médio

\footnotetext{
${ }^{14}$ CAPPELLETTI, Mauro e GARTH Bryant. Acesso à Justiça. Tradução de Ellen Gracie Northfllt. Porto Alegre: Sergio Antonio Fabris, 1998, p. 21.

15 SIRAQUE, Vanderlei. Controle Social da Função Administrativa do Estado. Possibilidades e limites na constituição de 1988. São Paulo: Saraiva, 2005, p. 36.

${ }^{16}$ IBGE - INSTITUTO BRASILEIRO DE GEOGRAFIA E ESTATÍ́STICA. Pesquisa Nacional por Amostra de Domicílios Contínua, Rio Grande do Norte, 2017. Disponível em <https://cidades.ibge.gov.br/brasil/rn/pesquisa/45/77295> acesso em 28/09/2019.
} 
habitual de $\mathrm{R} \$ 1.440,00$ (mil quatrocentos e quarenta reais). Partindo desse dado, temos que o valor mais baixo para as custas judiciais, $R \$ 184,21$ (cento e oitenta e quatro reais e vinte $\mathrm{e}$ um centavos), será aproximadamente $13 \%$ do valor recebido mensalmente, em média, pelo norte rio grandense, indicadores que comprovam a carência da nossa população.

A análise dos dados acima permite compreender o porquê de o TJRN atingir a marca de $78 \%$ de suas demandas agraciadas com o benefício da assistência judiciária gratuita, conforme os dados disponibilizados pelo CNJ em 2018 ${ }^{17}$. Invariavelmente, se muitos não pagam nada, poucos precisarão pagar muito. Assim, é possível suspeitar que a definição do formato de cobrança das taxas de serviços judiciais, no Rio Grande do Norte, não leva em consideração os indicadores apontados, bem como, é atingida pela ausência de sinalagma entre o serviço prestado e o valor cobrado.

Tudo isso, demonstra a ausência de razoabilidade dos valores definidos pelo Estado do Rio Grande do Norte para as custas judiciais, as quais deveriam optar por nova sistemática, pois uma parte dos possíveis jurisdicionados acaba por sofrer mais para acessar a jurisdição, vez que necessitará, muitas vezes, arcar com custos elevados para contrabalancear o sistema. Isto, evidentemente, causa um empecilho para o exercício do direito de ação em sentido amplo para parte da população.

\section{PROPOSTAS PARA DEFINIÇÃO DO VALOR DAS TAXAS JUDICIÁRIAS NO TJRN}

Diante do atual cenário, é prudente buscar uma solução que resolva, ou pelo menos minimize, os problemas apresentados. Para tanto, é necessário indicar uma saída satisfatória para o antigo debate entre valor da taxa e a equivalência com o custo da prestação do serviço jurisdicional no TJRN, evitando-se que a administração cobre valores tão maiores que o efetivamente gasto com o processo, bem como, que uns custeiem a prestação do serviço disposto a outros, violando o caráter retributivo das custas judiciais.

Portanto, será necessário tocar no cerne da discussão, indicando meio que melhor equacione o valor do tributo, determinando, para tanto, uma melhor relação entre a base de cálculo e a alíquota, efetivamente criando essa última, visto que o atual sistema opta por preços fixos sem uma aparente alíquota, a qual deverá ser definida de acordo com a complexidade e procedimento da demanda a ser proposta no TJRN.

Neste ponto, necessário observar que, a proposta, deverá permitir que as demandas mais simples, entendidas como aquelas que não exigem grande dilação probatória ou maior atuação do judiciário para encontrar a resposta ao mérito da demanda, sejam beneficiadas com custas reduzidas, de forma a tornar o ingresso judicial mais acessível aos jurisdicionados que, ordinariamente, não possuiriam condições de arcar com as custas cobradas no atual sistema, reduzindo a necessidade de concessões de assistências judiciárias gratuitas e melhor equilibrando a arrecadação.

Evidente que a solução não é fácil, contudo é possível propor um sistema que leve em consideração indicadores que melhor auxiliem no equilíbrio de todo o aparelho. Esse novo

17 CNJ - CONSELHO NACIONAL DE JUSTIÇA. Justiça em Números 2018. Disponível em <https://www.cnj.jus.br/wp-content/uploads/2011/02/8d9faee7812d35a58cee3d92d2df2f25.pdf>, acesso em 28/09/2019. 
formato, contudo, necessitará ser previsto em lei, conforme já assentou o STF no julgamento da $\mathrm{ADI} 1.378 \mathrm{MC}^{18}$, no qual restou definido que, em razão da natureza tributária das custas judiciais, é necessário que observe, dentre outros princípios, a legalidade e anterioridade.

Deve-se recordar que da análise do Texto Constitucional perpetrada em linhas pretéritas, com especial atenção dada ao disposto no art. 24, IV, percebeu-se que a definição das custas é matéria concorrente da União, dos Estados e do Distrito Federal. Entretanto, como até o presente momento a União permanece inerte em legislar sobre o tema, temos que os Estados vêm exercendo competência plena a esse respeito.

No Rio Grande do Norte, a publicação da Lei no Lei no 9.278/2009 dispôs sobre as custas processuais e emolumentos, optando por definir o valor da causa como a base de cálculo para as custas, não estabelecendo mecanismo eficaz que aproxime o valor cobrado do serviço prestado. Portanto, o primeiro ponto a esclarecer é quanto à necessidade de superação dessa norma, por meio da edição de lei que melhor corresponda aos anseios da razoabilidade. Contudo, quais seriam os elementos essenciais à nova norma?

Antes de responder a essa questão, é importante analisar opções diferentes da que o TJRN idealizou para a definição dos valores das custas judiciais, pois ante a inexistência de lei federal tratando do tema os Estados estão atuando com plena autonomia nessa matéria, havendo, portanto, divergências de opções quanto ao cálculo do valor do tributo. O CNJ, realizando estudo sobre o tema, afirmou:

\begin{abstract}
Apesar das especificidades encontradas nas unidades da federação, pode-se vislumbrar a existência de determinados padrões ou critérios de cobrança de custas. A sistemática de cobrança de custas mais comum (e adotada por dezessete estados) é baseada na cobrança variável em função do valor da causa. Por esse sistema, há a fixação de faixas de valores para as causas, sendo que para cada faixa há valores correspondentes para as custas e que são estabelecidos de forma crescente até determinados tetos ou valores máximos. Menos freqüente, porém adotado em sete unidades da Federação é o modelo de fixação de percentuais sobre o valor da causa, também marcado pela respectiva fixação de valores mínimos e máximos ${ }^{19}$.
\end{abstract}

O estudo do CNJ aponta que existem modelos alternativos aos que definem os valores das custas por meio de preços fixos, variáveis em razão do valor da causa ou em porcentagens sobre essa mesma base de cálculo. É o caso do Rio de Janeiro, que determina os valores das custas judiciais em valores fixos, mas que são diferenciados em razão da classe da demanda ajuizada. ${ }^{20}$

O que propomos para o Rio Grande do Norte, a fim de equacionar os problemas indicados, é um sistema que, buscando uma melhor sinalagma entre o valor cobrado e o

18 ADI 1.378 MC, rel. min. Celso de Mello, j. 30-11-1995, P, DJ de 30-5-1997, disponível em <http://www.stf.jus.br/portal/constituicao/artigobd.asp?item=\%201379>, acesso em 10/10/2019.

${ }^{19}$ CNJ - CONSELHO NACIONAL DE JUSTIÇA, Perfil da fixação de custas judiciais no Brasil e análise comparativa da experiência internacional. Departamento de Pesquisas Judiciárias, julho de 2010. Disponível em <https://www.conjur.com.br/dl/estudo-departamento-pesquisas.pdf>, acesso em 12/10/2019.

${ }^{20}$ Para uma melhor compreensão quanto a distinção das opções para o cálculo das custas judicias nos Tribunais de Justiças do Estados da Federação, recomenda-se a leitura do trabalho realizado pelo CNJ "Perfil da Fixação de Custas Judiciais no Brasil e a análise comparativa da experiência internacional". Disponível em: <https://www.cnj.jus.br/wp-content/uploads/2011/02/36-197-1-PB.pdf>. Acesso em: 11 dez. 2019. 
serviço efetivamente prestado, possua uma melhor caracterização retributiva com a existência de cotejo entre base de cálculo e alíquota efetivamente conhecida. Essa última, variando de acordo com a classe da demanda proposta e, evidentemente, com a definição de valor mínimo e máximo para custas judiciais a serem cobradas.

Ou seja, pretende-se a edição de norma adjetiva que estabeleça um novo formato para a definição dos valores cobrados a título de custas judiciais no TJRN. Tal norma, deverá seguir um sistema misto, caso comparado ao atual, pois manteria a base de cálculo, nos termos da Súmula 667 do STF, como sendo o valor da causa, mas utilizaria alíquotas para definir o quanto a ser cobrado pelas custas judiciais.

Entretanto, quanto à base de cálculo, seria prudente manter apenas parcialmente a divisão de faixas de valores da causa atualmente existente para definição do montante a ser cobrado. Pois, pretende-se a definição de alíquotas variáveis que incidiriam sobre tais faixas. Fato que tornaria necessário a definição do teto da base cálculo menor que o definido atualmente para aplicação da alíquota, sob pena de onerarmos em desmedidas as demandas de maior valor.

Nesse sentido, seria deveras importante a redução dos atuais $\mathrm{R} \$ \mathbf{2 . 0 0 0 . 0 0 0 , 0 0}$ (dois milhões de reais) para $\mathrm{R} \$ \mathbf{6 0 0 . 0 0 0 , 0 0}$ (seiscentos mil reais) como teto máximo de incidência da alíquota sobre o valor da causa, definindo-se, nesse patamar, o valor máximo das custas no TJRN. Tais alíquotas, portanto, incidiriam nas mesmas faixas de valores de causa já existentes, até o limite de $\mathrm{R} \$ 600.000,00$ (seiscentos mil reais).

Contudo, não seriam estas as únicas novidades, visto que as alíquotas seriam variáveis, a depender de alguns fatores como o procedimento: comum ou especial; a jurisdição: contenciosa ou voluntária; e, ainda, de acordo com assunto da demanda: família, execução de título extrajudicial e etc.

Ou seja, além da criação de uma alíquota, essa variaria a depender do tipo de procedimento, rito e tema da demanda submetida ao Poder Jurisdicional, sendo mais elevada para aquelas em que, ordinariamente, as fases processuais são mais longas e dispendiosas. Com isso, ter-se-ia uma melhor sinalagma para a fixação da exação e melhor equilibraria o sistema, visto que a alíquota seria a protagonista na definição mais justa dos valores cobrados.

Para uma melhor compreensão, voltemos ao exemplo das demandas que pretendiam a homologação do divórcio e a condenação de uma instituição financeira em reparação de danos morais pela demora excessiva na fila bancária. No caso relatado, o divórcio consensual possuía como valor da causa a quantia de $\mathrm{R} \$ 300.000,00$ (trezentos mil reais), enquanto que a demanda em que se pleiteava a reparação de danos morais, fora atribuída o valor de $\mathrm{R} \$$ $5.000,00$ (cinco mil reais).

De acordo com a proposta de alteração da norma que se pretende, seria necessário observar, no caso do divórcio, que estamos tratando de tema competente às Varas de Família, cujo procedimento será voluntário e não contencioso, enquanto que a demanda visando à reparação pelos danos morais sofridos será do procedimento ordinário e contencioso. Portanto, a título de ilustração, vejamos as propostas de tabelas para definição de custas para os casos analisados: 
O valor das custas processuais no Tribunal de Justiça no Rio Grande do Norte: uma nova proposta para sua definição

Tabela 2 - Proposta das custas judicias de depósito prévio na primeira instância, para Varas de Família, em procedimento voluntário, não contencioso.

\begin{tabular}{|c|c|c|c|}
\hline VALOR DA CAUSA & Alíquota & Valor Mínimo & Valor Máximo \\
\hline Até $\mathrm{R} \$ 10.000,00$ & $0,30 \%$ & $\mathrm{R} \$ 20,00$ & $\mathrm{R} \$ 30,00$ \\
\hline $\begin{array}{l}\text { Superiores a } R \$ 10.000,00 \text { ou até } \\
R \$ 30.000,00\end{array}$ & $0,35 \%$ & $\mathrm{R} \$ 35,00$ & $\mathrm{R} \$ 105,00$ \\
\hline $\begin{array}{l}\text { Superiores a } R \$ 30.000,00 \text { ou até } \\
R \$ 50.000,00\end{array}$ & $0,36 \%$ & $\mathrm{R} \$ 108,00$ & $\mathrm{R} \$ 180,00$ \\
\hline $\begin{array}{l}\text { Superiores a } \mathrm{R} \$ 50.000,00 \text { ou até } \\
\mathrm{R} \$ 100.000,00\end{array}$ & $0,37 \%$ & $\mathrm{R} \$ 185,00$ & $\mathrm{R} \$ 370,00$ \\
\hline $\begin{array}{l}\text { Superiores a } R \$ 100.000,00 \text { ou até } \\
R \$ 150.000,00\end{array}$ & $0,38 \%$ & $\mathrm{R} \$ 380,00$ & $\mathrm{R} \$ 570,00$ \\
\hline $\begin{array}{l}\text { Superiores a } R \$ 150.000,00 \text { ou até } \\
R \$ 200.000,00\end{array}$ & $0,39 \%$ & $\mathrm{R} \$ 585,00$ & $\mathrm{R} \$ 780,00$ \\
\hline $\begin{array}{l}\text { Superiores a } R \$ 200.000,00 \text { ou até } \\
R \$ 300.000,00\end{array}$ & $0,40 \%$ & $\mathrm{R} \$ 800,00$ & $\mathrm{R} \$ 1.200,00$ \\
\hline $\begin{array}{l}\text { Superiores a } R \$ 300.000,00 \text { ou até } \\
R \$ 400.000,00\end{array}$ & $0,41 \%$ & $\mathrm{R} \$ 1.230,00$ & $\mathrm{R} \$ 1.640,00$ \\
\hline $\begin{array}{l}\text { Superiores a } R \$ 400.000,00 \text { ou até } \\
R \$ 500.000,00\end{array}$ & $0,42 \%$ & $R \$ 1.680,00$ & $\mathrm{R} \$ 2.100,00$ \\
\hline $\begin{array}{l}\text { Superiores a } R \$ 500.000,00 \text { ou até } \\
R \$ 600.000,00\end{array}$ & $0,43 \%$ & $\mathrm{R} \$ 2.150,00$ & $\mathrm{R} \$ 2.580,00$ \\
\hline Acima de $R \$ 600.000,00$ & $0,43 \%$ & $\mathrm{R} \$ 2.580,00$ & $\mathrm{R} \$ 2.580,00$ \\
\hline
\end{tabular}

Fonte: própria.

Tabela 3 - Proposta das custas judicias de depósito prévio na primeira instância, para Varas de Cíveis, em procedimento ordinário, contencioso.

\begin{tabular}{|c|c|c|c|}
\hline VALOR DA CAUSA & Alíquota & Valor Mínimo & Valor Máximo \\
\hline Até $\mathrm{R} \$ 10.000,00$ & $0,50 \%$ & $\mathrm{R} \$ 30,00$ & $\mathrm{R} \$ 50,00$ \\
\hline $\begin{array}{l}\text { Superiores a } R \$ 10.000,00 \text { ou até } \\
R \$ 30.000,00\end{array}$ & $0,55 \%$ & $\mathrm{R} \$ 55,00$ & $\mathrm{R} \$ 165,00$ \\
\hline $\begin{array}{l}\text { Superiores a } R \$ 30.000,00 \text { ou até } \\
R \$ 50.000,00\end{array}$ & $0,56 \%$ & $\mathrm{R} \$ 168,00$ & $\mathrm{R} \$ 280,00$ \\
\hline $\begin{array}{l}\text { Superiores a } R \$ 50.000,00 \text { ou até } \\
R \$ 100.000,00\end{array}$ & $0,57 \%$ & $\mathrm{R} \$ 285,00$ & $\mathrm{R} \$ 570,00$ \\
\hline $\begin{array}{l}\text { Superiores a } R \$ 100.000,00 \text { ou até } \\
R \$ 150.000,00\end{array}$ & $0,58 \%$ & $\mathrm{R} \$ 580,00$ & $\mathrm{R} \$ 870,00$ \\
\hline $\begin{array}{l}\text { Superiores a } R \$ 150.000,00 \text { ou até } \\
R \$ 200.000,00\end{array}$ & $0,59 \%$ & $\mathrm{R} \$ 885,00$ & $\mathrm{R} \$ 1.180,00$ \\
\hline $\begin{array}{l}\text { Superiores a } R \$ 200.000,00 \text { ou até } \\
R \$ 300.000,00\end{array}$ & $0,60 \%$ & $R \$ 1.200,00$ & $\mathrm{R} \$ 1.800,00$ \\
\hline
\end{tabular}




\begin{tabular}{|l|l|l|l|}
\hline $\begin{array}{l}\text { Superiores a } R \$ 300.000,00 \text { ou até } \\
R \$ 400.000,00\end{array}$ & $0,61 \%$ & $R \$ 1.830,00$ & $R \$ 2.440,00$ \\
\hline $\begin{array}{l}\text { Superiores a } R \$ 400.000,00 \text { ou até } \\
R \$ 500.000,00\end{array}$ & $0,62 \%$ & $R \$ 2.480,00$ & $R \$ 3.100,00$ \\
\hline $\begin{array}{l}\text { Superiores a } R \$ 500.000,00 \text { ou até } \\
R \$ 600.000,00\end{array}$ & $0,63 \%$ & $R \$ 3.150,00$ & $R \$ 3.780,00$ \\
\hline Acima de $R \$ 600.000,00$ & $0,63 \%$ & $R \$ 3.780,00$ & $R \$ 3.780,00$ \\
\hline
\end{tabular}

Fonte: própria.

Diante das tabelas propostas, a demanda que se pretende a reparação por danos morais no valor de $R \$ 5.000,00$ (cinco mil reais) terá custas no montante de $\mathrm{R} \$ 30,00$ (trinta reais), enquanto que, na sistemática atual, seria de $R \$ 184,21$ (cento e oitenta e quatro reais e vinte e um centavos). No valor proposto, devem-se reduzir consideravelmente as concessões de assistência judiciária gratuita, visto que seis vezes mais acessível.

No mesmo diapasão, para o procedimento de divórcio consensual, no qual se pleiteia apenas a homologação por sentença, tendo a causa o valor de $\mathrm{R} \$ 300.000,00$ (trezentos mil reais), as custas assumirão o montante de $R \$ 1.200,00$ (um mil e duzentos reais), enquanto que na atual sistemática seria pago a quantia de $\mathrm{R} \$ 3.542,56$ (três mil quinhentos e quarenta e dois reais e cinquenta e seis centavos), um diferença de $\mathrm{R} \$ 2.342,56$ (dois mil, trezentos quarenta e dois reais cinquenta e seis centavos) que torna o sistema mais proporcional, sinalagmático e equilibrado.

Os exemplos são de grande valia, pois permitem uma clara demonstração da ideia proposta, ao ponto de demostrar que a criação de alíquotas variáveis em razão do valor da causa, tipo de procedimento e tema da demanda, permitiria um melhor equilíbrio na definição do montante das custas processuais em razão do efetivo serviço prestado pelo judiciário, trazendo uma maior razoabilidade ao sistema.

Ademais, quando se propõe uma sistemática que, dentre outras vantagens, permite a redução da necessidade de concessão de assistências judiciárias gratuitas, resolve-se a celeuma de que se muitos não pagam, poucos pagam muitos. É evidente a redução do valor das custas judiciais com a proposta apresentada, entretanto, isso não significa um impacto de grande monta na arrecadação, pois quase todos os jurisdicionados terão condições de pagar o tributo judicial, de forma que isso implica na necessária redução dos valores como um todo.

E mais, não deve ser a diminuição ou elevação da arrecadação a grande preocupação do sistema, pois não se trata de imposto e sim de tributo da espécie taxa cujas características, como demonstrado, estão ligadas a retribuição do serviço prestado e não com a contribuição para a administração pública. Portanto, a preocupação do sistema deverá ser com a maior sinalagma possível, para que cada contribuinte arque com o valor mais aproximado do custo gerado com seu processo. 


\section{CONSIDERAÇÕES FINAIS}

Diante do estudo realizado, demonstrou-se que as custas judiciais possuem natureza jurídica de tributo, da espécie taxa, portanto, devendo respeitar as necessárias características da espécie tributária na qual está inserida. Neste sentido, por possuir a característica da referibilidade, é necessário existir uma máxima correlação entre o serviço prestado e o valor cobrado, a fim de evitar um enriquecimento sem causa do Estado.

Encontrar uma efetiva sinalagma entre o valor cobrado a título de custas judiciais e o serviço jurisdicional prestado é o grande desafio a ser superado. A tarefa ficou ainda mais difícil pela ausência de legislação federal sobre o tema. Como a Constituição Federal definiu ser competência concorrente, cabendo a União a definição de norma geral, legislar sobre custas judiciais, os Estados, diante da omissão da União, legislam com evidente liberdade sobre o assunto.

Gozando dessa liberdade, o Rio Grande do Norte, editou a Lei ำ 9.278, de 30 de dezembro de 2009, regulamentando a cobrança das custas processuais, emolumentos, fundo de compensação dos registradores civis das pessoas naturais e taxa de fiscalização, bem como, definindo o valor da causa como a base de cálculo da taxa de serviço judicial, concebida como custas judicias.

No entanto, optou pela criação de uma tabela na qual os montantes cobrados, no TJRN, variam de acordo com intervalos de valores das causas, optando por preço fixo para a exação, sem definição de uma alíquota, fato que não é próprio da espécie tributária taxa, pois impede que, dada a natureza vinculante desse tributo, exista uma exata correlação entre o serviço prestado e o montante efetivamente cobrado.

Portanto, a opção escolhida para o TJRN gera uma ausência de razoabilidade nas importâncias cobradas para determinadas lides, pois existem demandas com procedimentos simplificados as quais possuem o mesmo custo de ajuizamento que outras de procedimentos mais complexos e longos. E mais, os altos valores cobrados exigem uma maior concessão da gratuidade judiciária, de forma que muitos não pagam nada, exigindo que poucos paguem muito. Esse cenário abala o acesso à jurisdição, visto que não foi criado mecanismo eficaz de aproximação do valor cobrado para com relação ao serviço prestado.

Por essa razão, propõe-se um novo modelo para realização do cálculo do valor das custas processuais no TJRN. Para tanto, indica-se um sistema misto, quando comparado ao atual, em razão de aproveitar algumas de suas características, como a base de cálculo e a existência de valor mínimo e máximo para o montante a ser cobrado. Entretanto, com a inclusão de elemento novo, capaz de equilibrar todo o sistema.

O novo elemento, protagonista da reformulação, seria a criação de alíquotas variáveis em razão de algumas características da demanda a ser proposta para, só então, ser realizada a sua quantificação. Portanto, as alíquotas, hoje inexistentes, seriam criadas e definidas de acordo com o tipo de jurisdição, procedimento e natureza da demanda. Ou seja, seriam aplicadas alíquotas, sobre os valores da causa, maiores para os procedimentos mais complexos e menores para os procedimentos mais simples.

A própria criação de alíquotas variáveis em razão de certos fatores, permitiria uma readequação dos valores cobrados, tornando-os mais acessíveis para muitos jurisdicionados 
que hoje necessitam do benefício da gratuidade judiciária. Com isso, haveria uma melhor redistribuição dos custos, com uma maior sinalagma entre preço e serviço, resolvendo a contenda de muitos não pagarem nada no atual sistema, fato que exige que poucos precisem pagar muito para acessar a jurisdição no TJRN.

Portanto, o que se propõe é uma evidente reformulação do atual sistema, por meio da superação da ausência de alíquotas, dando a estas, características de variabilidade em razão de algumas propriedades pré-definidas as quais permitam que as taxas de serviços judiciais cobrados pelo TJRN atinjam uma melhor razoabilidade, caracterizada pela maior proximidade entre o valor cobrado e o serviço prestado.

\section{REFERÊNCIAS}

AMARO, Luciano. Direito Tributário Brasileiro. 14a ed. São Paulo: Saraiva, 2008, p. 31.

BRASIL. Supremo Tribunal Federal. ADI 1444, Relator(a): Min. SYDNEY SANCHES, Tribunal Pleno, julgado em 12/02/2003, DJ 11-04-2003 PP-00026 EMENT VOL-02106-01 PP-00046

Supremo Tribunal Federal. Ação Direta de Inconstitucionalidade no 3.826. Tribunal

Pleno. Ministro Relator: Eros Grau, julgamento em: 12-5-2010, DJE 154 de 20-8-2010. Disponível em:

<http://www.stf.jus.br/portal/jurisprudencia/menuSumarioSumulas.asp?sumula=2250>.

Supremo Tribunal Federal. ADI 1.378 MC, rel. min. Celso de Mello, j. 30-11-1995, P, DJ de 30-5-1997, disponível em <http://www.stf.jus.br/portal/constituicao/artigobd.asp?item=\%201379>.

IBGE. Cidades. Disponível em <https://cidades.ibge.gov.br/brasil/rn/pesquisa/45/77295>.

CAPPELLETTI, Mauro e GARTH Bryant. Acesso à Justiça. trad. de Ellen Gracie Northfllt. Porto Alegre: Sergio Antonio Fabris, 1988.

COÊLHO, Sacha Calmon Navarro. Contribuições no Direito Brasileiro. In: MARTINS, Ives Granda da Silva; Mendes, Gilmar Ferreia (coord). Tratado de Direito Constitucional, 2ª ed. São Paulo, 2012.

CONSELHO NACIONAL DE JUSTIÇA, Perfil da fixação de custas judiciais no Brasil e análise comparativa da experiência internacional. Departamento de Pesquisas Judiciárias, julho de 2010. Disponível em <https://www.conjur.com.br/dl/estudo-departamento-pesquisas.pdf>

Justiça em Números 2018. Disponível em https://www.cnj.jus.br/wpcontent/uploads/2011/02/8d9faee7812d35a58cee3d92d2df2f25.pdf, acesso em 28/09/2019.

MORAES, Bernardo Ribeiro de. Doutrina e prática das taxas. São Paulo: RT, 1976, p. 108, apud, SABBAG, Eduardo. Manual de Direito Tributário. 9ạ ed. São Paulo: Saraiva, 2017. 
Rio Grande do Norte, Resolução no 4, do TJRN, de 21 de fevereiro de 2018. Disponível em $<$ https://corregedoria.tjrn.jus.br/index.php/extrajudicial/custas-e-emolumentos/13588-1444/file>

SIRAQUE, Vanderlei. Controle Social da Função Administrativa do Estado. Possibilidades e limites na constituição de 1988. São Paulo: Saraiva, 2005.

TORRES, Ricardo Lobo. Curso de direito financeiro e tributário. 3a ed. Rio de Janeiro: Renovar, 1996.

VILLEGAS, Hector. Verdades e fiç̧ões em torno do tributo denominado taxa. Revista de Direito Público, São Paulo, no 17, apud ATALIBA, Geraldo. Hipótese de Incidência Tributária. São Paulo: Malheiros, 2004.

ZANCANER, Weida. Razoabilidade e moralidade: princípios concretizadores do perfil constitucional do estado social e democrático de direito. Revista Diálogo Jurídico, Salvador, CAJ - Centro de Atualização Jurídica, ano I, no. 9, dezembro, 2001. Disponível em: <http://www.direitopublico.com.br>. Acesso em: 14 de dezembro de 2019. 